públicas y abiertas; desde ellas se presentan a las elecciones sindicales y a toda autoridad o jerarquía viviente, ganando la legalidad de facto, que de eso se trataba.

En el capítulo dedicado a Andalucía, aunque he sido testigo del esfuerzo realizado por Rafael Morales Ruíz, sus autores incurren en una contradicción inducida, que no me resisto a comentar.

En la página 236, en la letra pequeña, coinciden con Joe Foweraker, que en su obra dice que «los militantes de CC.OO. no eran exactamente protagonistas prodemocráticos". Sin embargo, los mismos autores, más adelante, en la página 323, volviendo a citar el libro de Joe, certifican que «CC.OO. y el PCE fueron la punta de lanza de la lucha democrática y tuvieron éxito en dicha misión". ¿En qué quedamos?

Este tomo de la historia de CC.OO. es bueno, es denso, abierto y participativo. Como su director y presentador dice, no ha pretendido sacar conclusiones definitivas sobre temas importantes de nuestra historia reciente. Pero a partir de él, de su sistemática, se puede abordar su reedición ampliada, al menos en tres tomos. Así lo animo y espero.

Si con esta crítica realizada a petición de mi buen amigo Carlos Arenas, logro despertar curiosidades para su compra y lectura, entraria en este inquietante año de 1996 satisfecho y feliz.

JOAQUIN AURIOLES - JUAN A. LACOMBA - EDUARDO CUENCA - MANUEL MARTIN MANUEL DELGADO - CARLOS ROMAN - FRANCISCO FERRARO - JUAN TORRES Ariel - Barcelona, 1995

\title{
OCHO ECONOMISTAS ANTE LA REALIDAD ECONOMICA DE ANDALUCIA
}

OSCAR OVIDIO CABRERA MELGAR *

Uno de los propósitos de esta recensión es dar a conocer de una manera sucinta una serie de ocho ponencias elaboradas por un conjunto de profesores de las Universidades Andaluzas y cuya temática gira en torno al «análisis de la situación económica de Andalucían, siendo abordada por los ponentes

* Economista. Banco Central de El Salvador. 
desde varios enfoques que van desde la evolución de la estructura económica andaluza, el papel de la región en el entorno internacional, antecedentes históricos y el papel del sector público como potenciador de la región. Este seminario fue expuesto en la primavera de 1994 en la Facultad de Ciencias Económicas y Empresariales de la Universidad de Sevilla, siendo organizado por el Departamento de Economía Aplicada II y el Instituto de Desarrollo Regional -Fundación Universitaria-, con el objetivo de contribuir al debate en el conocimiento de la economía andaluza, su componente secular y los desafíos que se le presentan a la región en el proceso de globalización e integración.

La primera ponencia inicia presentándonos los «Retos e incertidumbres económicas en la Andalucía de los 90", investigación desarrollada por el profesor Joaquín Aurioles y cuyo objetivo es analizar la evolución del perfil subyacente que ha presentado la economía andaluza en la década de los ochenta y la primera mitad de los noventa, quince años donde su evolución ha pasado de un período de expansión económica a una recesión de grandes dimensiones y que ambos períodos comparten ciertos rasgos de naturaleza estructural, tales como: 1) desarticulación de las relaciones de producción manifestada en una pérdida de participación de los sectores agrario e industrial en el VAB y sin capacidad de inteconexiones intersectoriales, alto componente importado en la producción regional, una dominancia de los servicios en la producción. 2) en la demanda, la economia andaluza presenta una mayor dependencia con el exterior en sus necesidades de financiación - gasto público y capitales exteriores-. A juicio del profesor Aurioles todo lo anteriormente expuesto hunde sus raíces en tres causas: $1^{\mathbf{a}}$ una crisis económica internacional que aqueja la economía europea -española y andaluza en particular-y que se manifiesta en una amplificación en fases de recesión en la destrucción de empleo - dificultad de creación de empleos en fase de crecimiento económico-, pérdida de competitividad relativa, altos niveles de deuda pública, sin embargo, se advierte que la Unión Europea (UE) y los países miembros han centrado esfuerzos para su corrección. $2^{\mathbf{a}}$ una crisis interna del aparato productivo y su efecto más evidente es las altas tasas de paro por encima de la media nacional y, $3^{\mathrm{a}}$ una crisis institucional en donde se pone en juego el papel del sector público, hasta hoy, potenciador del desarrollo económico y social. Finaliza la ponencia con una serie de propuestas de solución a la crisis que padece la región andaluza.

En la segunda conferencia, el profesor Eduardo Cuenca García, aborda el estudio de los efectos del proceso de mundialización de las economías y la integración europeas en la estructura económica y social andaluza. En de la opinión que Andalucía debe centrar en gran medida el interés por el estudio de las variables externas relacionadas con la competitividad regional -exportaciones, importaciones, movilidad de la mano de obra, los capitales, los ser- 
vicios y la información. Pasa revista a las principales limitaciones de la economía andaluza que van desde los puramente seculares hasta los derivados de su integración al mercado único; en el sector agrario desmenuza las transformaciones en cuanto el grado de mecanización, especialización y su adaptación a la Política Agrícola Común (PAC); en el sector industrial la debilidad en su participación en $\mathrm{VAB}$, la concentración de la producción en tres zonas geográfica, reducción del empleo; finalmente, los servicios pese a su aumento de la producción y su aportación al producto final presenta presiones inflacionistas y falta de utilización de recursos tecnológicos (pág. 43).

Finaliza el autor, definiendo a la región como una economía apoyada en sectores tradicionales. En el comercio exterior se apoya en un reducido número de productos y sin articular la estructura productiva, a lo que es necesario aumentar la competitividad andaluza; el proceso de "modernización" desarrollado desde su integración en la UE hace necesario su óptimo aprovechamiento en el futuro de la región (pág. 61).

El profesor Manuel Delgado Cabeza en su conferencia «La economía andaluza en los años 90, rasgos básicos y perspectivas», tiene por objeto el evaluar las posibilidades y perspectivas de la economía andaluza centrándose en el estudio de la relación tradicional entre el proceso de producción y las formas de apropiación del excedente con especial énfasis en el sector agricultura. El autor nos revela la especialización productiva -la economía andaluza se centra en la explotación de los recursos naturales agrícola y agroalimentario, Construcción y Minerales metálicos-, la desarticulación existente -según las TIO de 1980, 1990, las relaciones intersectoriales son básicamente las mismas con algunas matizaciones-, la poca capacidad de crear empleo, la distribución concentradora de los beneficios en el sector agricola -éste ha reducido su participación al VAB de 75.6\% en 1980 a $67,6 \%$ en 1990 , también las remuneraciones al factor trabajo de $24,4 \%$ al $14 \%$, respectivamente-, su heterogeneidad estructural - la divergencia entre los sectores modernizantes y autóctono-. Abreviando en una cita del profesor Delgado, el modelo de producción y distribución andaluz y sus perspectivas

"Por eso, dentro de este modelo, y mientras que no tengan lugar profundas transformaciones en la forma en que se produce y se distribuye la riqueza en Andalucia, el crecimiento reproduce y amplia las desfavorables condiciones de partida, acentuando los desequilibrios, incrementando las desigualdades profundizando la polarización en el sistema productivo. El. crecimiento, lejos de ser solución es, en gran medida, el problemaw.

El autor examina las tendencias de la economía mundial y el papel predominante del capital transnacional configurando y determinando él desa- 
rrollo económico y social andaluz al establecer alianzas con el capital autóctono - pequeño y mediano-. Al mismo tiempo, el proceso de globalización e integración europea va dando visos de un desarrollo divergente entre los centros y la periferia, hipótesis que afirma Hadjimichalis (pág. 97). Por otro lado la tendencia a la reducción del papel del sector público en el mercado está sufriendo un retroceso como factor de reducción de los desequilibrios regionales.

Finalmente el autor, con el título «Un norte distinto", plantea un estilo de desarollo en donde la ciencia econía debe superar ciertos esquemas: la consideración de una ciencia exacta u objetiva y la vuelta a las preposiciones éticas, la conjugación del análisis económico con lo social y la inclusión de lo económico y lo físico con el fin de renovar «el interés de los valores de uso sobre los valores de cambion.

La ponencia "Algunas consideraciones sobre la política económica de la Junta de Andalucía", elaborada por el profesor Francisco José Ferraro García, tiene como objeto mostrar el desarrollado la política económica de la Junta de Andalucía en el período 1990-1994, analizando previamente los antecedentes del Estado de las Autonomías y centrándose en el análisis del Plan Andaluz de Desarrollo Económico 1991-1994 (PADE).

La coherencia del nuevo Gobierno andaluz en el uso de la planificación regional como instrumento para mejora las ineficiencias surgidas de las fuerzas del mercado. Las experiencias obtenidas por la Junta de Andalucía en la elaboración y ejecución de los planes anteriores, revistió al PADE 1991-1994 de mecanismos novedosos, como una mejor coordinación en las metas y objetivos e instrumentos con los desembolsos de invesión.

Se dan circunstancias favorables en las que se desarrolla el PADE 19911994, tales como: consolidación de la administración autonómica, un proceso de concertación entre sindicatos y empresarios respecto a los objetivos del plan, un aumento en las dotaciones de infraestructuras. Por otro lado, el autor en su ponencia resalta ciertas circunstancias desfavorables al PADE 1991-1994: recesión económica en los países desarrollados, una mayor restricción presupuestaria en la ejecución, incapacidad de la economía andaluza de crear trabajo, fase recesiva en la economía española y andaluza, desarticulación productiva, pérdida de competitividad de la industria andaluza. Los objetivos contemplados en el PADE van desde: la articulación del tejido productivo y del territorio, la revalorización de los factores productivos, preservar el medio ambiente y de carácter social y cultural, y la mejora de la calidad de vida (pág. 115). Los instrumentos que posibilitan el logro de los objetivos son: políticas de sectores, factores, territorial y social.

En el PADE se articulan otra serie de planes y programas como son: Plan de desarrollo Integral del Turismo en Andalucía, Programa Industrial 
para Andalucía 1994-1997, Plan energético de Andalucía 1994-2000, Programa para la mejora de la Comercialización de la Empresa Andaluza y el Plan de Desarrollo Rural para Andalucía.

La quinta conferencia desarrollada por el profesor Juan Antonio Lacomba, analiza desde una perspectiva histórica el análisis de las upermanencias" y los "cambios" que va presentando la realidad económica y social andaluza. El estudio arranca en el cambio en el perfil del crecimiento que mostraba Andalucía en el segundo tercio del siglo XIX, período en el cual el autor define el germen de la dependencia de la región en su integración económica mundial. En este momento de la historia Andalucía presenta algunos rasgos que lo confirman o permanencias:

"a) desequilibrada estructura de la propiedad agraria y excesivo "tradicionalismo" en la agricultura...; b) fuerte proceso de "desindustrialización'... por la progresiva caída del mercado regional, prácticamente sin integración; c) extracción continua de beneficios hacia el resto de España o hacia el extranjero.... (págs. 141 y 142).

En la primera mitad del siglo XX, Andalucia presenta la misma tendencia de desestructuración de la economía junto a una marcada dependencia de la región. En el sector agrícola, pese a algunos cambios persiste la concentración de la riqueza, a juicio del autor de a agudización de sus problemas en su estructura económica comparada. En el sector industrial se da una "colonización" de la industria regional a manos del capital extranjero. Unido a otro conjunto de problemas tales como: falta de financiación interna para posibilitar un crecimiento desde adentro, subutilización de mano de obra y recursos naturales (pág. 144).

Los años sesenta presentan otro punto de inflexión en la economía andaluza con su articulación en la economía mundial partiendo de condiciones desventajosas con una estructura dependiente en la agroindustria y los servicios y una falta de relaciones intersectoriales, características permanentes con la que se encuentra la región en la hora de su integración en la CEE. En opinión del profesor Lacomba los resultados para Andalucíaw... ha funcionado como mecanismo 'regresivo' para el desarrollo de la economía andaluza... Todo viene a apuntar, pues los aspectos negativos de algunas políticas comunitarias -en particular-, la PAC para Andalucía» (pág. 146).

En suma, el autor finaliza mostrándonos el peso de la historia, como variable explicativa del proceso de producción y las formas de apropiación del excedente con las expresiones más crudas como el paro estructural, el carácter dependiente de la economía al ciclo económico internacional.

La conferencia del progesor Manuel Martín Rodríguez denominada «Estribos y algaidas de la economía andaluzam, viene a complementar 
la ponencia anterior renovando el interés del análisis económico de medio y largo plazo en contraposición a lo que a opinión del autor el estudio del modelo de desarrollo de la economía andaluza "habían ido cediendo el paso poco a poco a simples estudios sectoriales o puntuales en el muy corto plazon (pág. 158). La estructura de la ponencia inicia en un análisis de la evolución de la economía regional en el período 1973-1991, con énfasis en la industria manufacturera, el fenómeno estructural de escasa creación de empleo. Finaliza con evaluación del poder autonómico y los planes de desarrollo regional.

El profesor Carlos Román, titula su coloquio «Andalucía dentro de su contexto", inicia su aportación en tres partes: la primera con la evolución estructural y coyuntural de la economía andaluza en el período 1976 - la entrada de España a la CEE - a la actualidad, desentrañando los aspectos positivos y negativos de la integración al mercado único europeo. La segunda, valora el entorno internacional en el que se circunscribe Andalucía y los retos más importantes en lo demográfico, tecnológico, medioambiente y el nuevo papel del Estado. Concluye contestando las tradicionales interrogantes, qué, cómo y para quién puede producir la economía andaluza (pág. 178).

«Crecimiento económico y distribución de la renta en Andalucía. Viejos problemas, excusas modernas", es la octava ponencia elaborada por el profesor Juan Torres López y con que finaliza el libro. El objeto de ella, es desentrañar el proceso de distribución de las rentas en Andalucía como parte inherente al modelo de producción imperando en la región y, reflexionar las formas de hacer frente al empobrecimiento, la dependencia a las transferencias de amplios sectores de la población y el impulso del crecimiento sobre el aumento de los beneficios del sector privado como lógica de la competitividad. Concluye, que la equidad debe ir de la mano del crecimiento económico sino afectará a éste (pág. 238). 